Available online on 15.07.2018 at jddtonline.info
Open Access to Pharmaceutical and Medical Research
commercial use, provided the original work is properly cited

Open $\overbrace{\text { Access }}$

Review Article

\title{
Overview on Chemokine Co-Receptor-5 (CCR-5) HIV-1 Entry Inhibitors
}

\author{
Pant Kavita*, Singh Anita \\ Department of Pharmaceutical Sciences, Kumaun University Campus Bhimtal, Nainital-263136, Uttarakhand, India
}

\begin{abstract}
In the 21st century, HIV-1 has turned into a noteworthy global challenge in medication. As per WHO report 2017, HIV is one of the deadliest diseases adding to an aggregate of 36.7 million contaminations until December 2016 among which 1.8 million were analyzed in 2016 itself. In 2016, 19.5 million individuals experienced to anti-retroviral treatment summing up to US\$ 11 billion. With regards to rising resistance from anti-retroviral medication in HIV treatment, the advancement of most recent medication classes with a newer mode of action stays essential. The CCR5 co-receptor inhibitors suppress the fusion of HIV with the host cell by upsetting the connection of gp-120 protein with the CCR5 receptor. Though severalCCR5 antagonists are assessed in clinical trials, just Maraviroc has been endorsed for clinical use in the treatment of HIV infected patients. The efficacy and safety profile of CCR5 adversaries with a consideration on maraviroc are assessed here in conjunction with their use in newer and developing clinical trials. In the beginning time of HIV-1 infection in the most of patients, the HIV utilizes CCR5 receptor for passage in CD4 cell of the host (CCR5-tropic infection). Maraviroc did not decrease virus load (compared to optimized background therapy) in patients with CXCR4 or dual-tropic virus. Before prescribing a CCR5 blocker HIV tropism testing is recommended. Viral tropism is defined as the capability of the viruses to enter as well as infect the host cell, and it is based on the binding capacity of the viruses to receptors on those host cells. The co-receptor type should be recognized before the treatment started with a CCR5 blocker.
\end{abstract}

Keywords: CCR5, CXCR4, HIV-1, CD4 cell, Tropism, CYP3A4.

Article Info: Received 21 May, 2018; Review Completed 09 July 2018; Accepted 10 July 2018; Available online 15 July 2018

Cite this article as:

Kavita P, Anita S, Overview on Chemokine Co-Receptor-5 (CCR-5) HIV-1 Entry Inhibitors, Journal of Drug Delivery and Therapeutics. 2018; 8(4):73-79 DOI: http://dx.doi.org/10.22270/jddt.v8i4.1794

*Address for Correspondence:

Pant Kavita, Department of Pharmaceutical Sciences, Kumaun University Campus Bhimtal, Nainital-263136, Uttarakhand, India

\section{INTRODUCTION}

In the 21st century, HIV-1 has turned into a noteworthy global challenge in medication. As per WHO report 2017, HIV is one of the deadliest diseases adding to an aggregate of 36.7 million contaminations until December 2016 among which 1.8 million were analyzed in 2016 itself. In 2016, 19.5 million individuals experienced to anti-retroviral treatment summing up to US\$ 11 billion. In between 2000 and 2016, new HIV infections fell by $39 \%$, and HIV-related demises reduced by $33 \%$ with 13.1 million lives spared due to ART in an exceedingly similar period ${ }^{1}$. In AIDS the system becomes compromised and is unable to fight infections ${ }^{2}$, 3 . Due to resistance to many antiretroviral drugs, development of new classes of drugs with a new mode of action is essential. The main productive route for HIV treatment is HAART. It is a mix of different antiretroviral drugs (turn around transcriptase inhibitors, protease inhibitors, integrase inhibitors, co-receptor inhibitors and combination inhibitors). In contrast with different classes, the CCR5 inhibitor is a novel class of HIV-1 inhibitors for HIV-1 treatment approved in recent years. Disclosure of common ligands of CCR5macrophage inflammatory protein1- $\alpha$ (MIP1- $\alpha$ ), RANTES (Regulated upon initiation, Normal T-cell communicated and discharged), and macrophage inflammatory protein1- $\beta$ (MIP1- $\beta$ ) - as inhibitors quickly discover a method for examine for manufactured ligands to repress the HIV-1 receptor and hinders the viral entry to the cell ${ }^{4}$. The CCR5 receptor is a major co-receptor for viral entry in the host cell, and it is a class of G-protein coupled receptor family having an essential role in the R5- tropic HIV-1 entry. 


\section{DEVELOPMENT STAGES}

Till now few CCR5 inhibitors are investigated for AIDS treatment. In August 2007 USFDA approve the only drug Maraviroc (Selzentry). Aplaviroc trial was discontinued because of its hepatotoxicity found during clinical trials ${ }^{5}$. INCB009471 an oral antagonist of the CCR5 receptor with prolonged half-life was studied for phase I and II in 2007, but the trials were discontinued by the company. Another drug Vicriviroc was in phase III clinical trial ${ }^{6,7}$ and halted. Anibamine, the first natural product obtained from Aniba spp., contains quaternary pyridine alkaloids that are potent CCR5 inhibitors ${ }^{8}$. Recently, there are two new potent CCR5 inhibitors discovered by Takeda (TAK-651 and TAK-220). TAK652 reported to be a potent inhibitor of CCR5 in preclinical trials and is under phase I pharmacokinetic studies. Promising results of TAK-220 has been found in preclinical stages ${ }^{9}$.

\section{ROLE OF CCR5 IN HIV/AIDS}

For HIV-1 to enter into a host cell, binding with the CD4 envelope receptor is essential. When HIV-1 binds to the CD4 receptor conformational changes occur in gp120 and the CCR5 binding site is exposed. By this process second conformational change produces in gp 41 protein of HIV-1, resulting in fusion of two membranes and viral entry into host cell. Interestingly, Caucasians (1\%) in their CCR5 gene has a deletion of homozygous 32 base pairs. In Caucasian individuals expression of CCR5 on the cell surface of $\mathrm{CD} 4$ is absent which gives protection against acquiring HIV-1 infection ${ }^{10}$.Two main approaches for blocking the entry mechanism of virus entry to host cell is either by interference with protein that binds to CCR5 or by removing the CCR5 from cell surface through carboxy terminus phosphorylation of CCR5.

\section{WHY TROPISM ASSAY IS REQUIRED?}

In the early stage of HIV-1 disease in the majority of patients, the virus uses CCR5 receptor for entry in CD4 cell of the host (CCR5-tropic virus). In cases of advanced immuno-suppression around one-half of viral strains enters either through CXCR4 receptor alone, or both CXCR4 and CCR5 receptors (R4 or dual-tropic). About $80 \%$ of the HIV-naïve patients are infected with the R5 tropic virus, while approximately $50 \%$ of the pretreated patients of the HIV-1 are exclusively infected with CCR5 viral strains. For patients, solely infected with CCR5 tropic viral strains maraviroc has been approved. Maraviroc did not decrease virus load (compared to optimized background therapy) in patients with CXCR4 or dual-tropic virus ${ }^{11}$.

\section{European guidelines for the tropism assay}

Viral tropism is defined as the capability of the viruses to enter as well as infect the host cell, and it is based on the binding capacity of the viruses to receptors on those host cells. Before prescribing a CCR5 blocker HIV tropism testing is recommended. The co-receptor type should be recognized before the treatment started with a CCR5 blocker ${ }^{12}$. Tropism testing is powerfully suggested in all patients who have medicine failure for whom a CCR5 antagonist is being thought about as a part of the following programme. Tropism testing is moderately counseled altogether patients for whom treatment has did not give insight into future treatment choices. Patients showing adverse events along with its current regimen or unexplained neurological pathology, treatment containing CCR5 co-receptor inhibitors will be of potential worth. In patients who have been diagnosed recently, the role of tropism assay as an indicator for future use of CCR5 antagonist or as a prognostic marker is not sufficiently illustrious to justify any recommendation ${ }^{13}$. In antiviral-naïve patients at high risk of hepatotoxic and neurological abnormalities of first-line treatment, CCR5-tropism testing could be done before initiating any therapy so, if toxic effects develop, a procedure will be changed to include CCR5 antagonists without further tests. Samples ought to be collected as close as possible to the time of beginning treatment. The utilization of maraviroc in HIV-naïve patients is not approved by the European Medicines Agency $^{12}$. Tropism is often assessed with either genotypic or phenotypic technique.

Table1: Some critical methodological characteristics of several phenotypic recombinant method strends within the last years to assess HIV tropism.

\begin{tabular}{|c|c|c|c|c|}
\hline \multirow{2}{*}{$\begin{array}{l}\text { Name of the Phenotypic } \\
\text { recombinant way }\end{array}$} & \multicolumn{4}{|c|}{ Key methodological characteristics } \\
\hline & vector Construction & Report gene & Virus Stocks & Sensitivity \\
\hline XtrackC/PhenX-R In Pheno AG & Clonal technology & $\beta$-galactosidase & Defective Replication & $1 \%$ \\
\hline Virco NH2-V4 gp120 & Recombination & $\begin{array}{l}\text { green fluorescent } \\
\text { protein }\end{array}$ & Competent Replication & $5-10 \%$ \\
\hline $\begin{array}{l}\text { Monogram Biosciences } \\
\text { ESTATrofileTM4 }\end{array}$ & $\begin{array}{l}\text { Clonal } \\
\text { Technology }\end{array}$ & Luciferase & Defective Replication & $0.3-1 \%$ \\
\hline $\begin{array}{l}\text { Univ. Toulouse Toulouse } \\
\text { Tropism Test (TTT) }\end{array}$ & Recombination & Luciferase & Competent Replication & $0.5 \%$ \\
\hline ISCIII-FISPE Tropitest & $\begin{array}{l}\text { Clonal } \\
\text { Technology }\end{array}$ & Luciferase & Competent Replication & $1 \%$ \\
\hline VIRalliance Phenoscript & Recombination & $\beta$-galactosidase & Competent Replication & $5-10 \%$ \\
\hline
\end{tabular}




\section{Phenotypic Assay}

The phenotype assays are ordinarily based entirely on recombinant virus's technology. Briefly, the gene is amplified with the aid of PCR (Polymerase Chain Reaction) from plasma samples. In the end, recombinant virions are generated through genetic or clonal recombination. The recombinant virus debris is used to infect cell lines expressing the CD4 receptor and both CCR5 or CXCR4. The phenotypic assay Trofile ${ }^{\mathrm{TM}}$ has been appreciably used to provide tropism knowledge in the maraviroc trials, and hence it's been the most extensively used up to now ${ }^{13-15}$.

\section{Genotypic Assay}

Genotypic assays constitute an extra viable opportunity to phenotypic assays for the reason that they're speedier, less expensive, and extensively to be had among laboratories that specialize in HIV diagnosis. During the early 1990s, numerous rules, and algorithms had been developed to expect HIV co-receptor usage based entirely on V3 sequences, lots of them at the moment are free to be had through publicly accessible websites. The "11/25 rule" was the earliest algorithm advanced for viral tropism interpretation and remained one of the most famous till current times. It's far primarily based on the truth that viruses offering essential amino acids such as arginine $(\mathrm{R})$ or lysine $(\mathrm{k})$ at positions 11 and 25 are regularly related to an X4-tropic phenotype. Conversely, non-existence of $\mathrm{R}$ or $\mathrm{K}$ in those areas is related to R5-tropic viruses ${ }^{16}$. Despite the fact that this rule shows high specificity (80-90\%), it can be afflicted by low sensitivity (30-40\%) in figuring out X4-tropic viruses in contrast with phenotypic assays. Currently, a modification of the $11 / 25$ rule has been proposed that improves the predictive cost for viral tropism. It is regarded as the 11/24/25 rule and considers variants as $\mathrm{X} 4$-tropic when a position 11,24 , or 25 harbours any essential amino acid; otherwise the virus is classed as R5-tropic ${ }^{17}$.

The "net charge rule" is a simple interpretation technique that estimates the global net cost of the V3 region in keeping with the following formula:

$$
(\mathrm{k}+\mathrm{R})-(\text { aspartic acid }[\mathrm{D}]+\text { glutamic acid }[\mathrm{E}]) \text {. }
$$

If the end result is $\geq 5$, the virus is assessed as $\mathrm{X} 4$ tropic; in any other case, it is miles R5- tropic. There is another rule for calculating the net charge that consists of the primary amino acid histidine $(\mathrm{H})$; this is as follows:

$$
(\mathrm{k}+\mathrm{R}+\mathrm{H})-(\mathrm{D}+\mathrm{E}) \text {. }
$$

But, this alternative approach is much less correct than the guideline that does not include $\mathrm{H}$ (79 vs $49 \%$ ). Similar to the $11 / 25$ rule, the net charge rule indicates excessive specificity but suffers from low sensitivity in figuring out X4 variants ${ }^{18,19}$. During the last decade, efforts have been made to discover residues in the V3 area which can be involved in determining viral tropism. The natural variability of the V3 location has been examined in a couple of HIV isolates phenotypically categorized as R5- and X4-tropic. Consequently, new residues and particular patterns of amino acids have been recognized as influencing viral tropism. No one trade appears to be responsible for the tropism; as a substitute, numerous clusters of genotypes seem in large part decide viral tropism ${ }^{20,21}$. Many algorithms are free to be had on websites such as Wetcat, Geno2phenocoreceptor, net PSSM, and Fortinbras PSSM.

Table 2: Some critical methodological characteristics of several genotypic recombinant methods trends within the last years to assess HIV tropism

\begin{tabular}{|l|l|l|l|}
\hline \multirow{2}{*}{$\begin{array}{l}\text { Name of the Genotypic } \\
\text { Methodology }\end{array}$} & \multicolumn{3}{|c|}{ Key methodological characteristics } \\
\cline { 2 - 4 } & \multicolumn{1}{|c|}{ Principle } & Sensitivity & Specificity \\
\hline $11 / 25$ rule & R or K at position 11/or 25 is related to an X4-tropic makeup & $59.5 \%$ & $93.4 \%$ \\
\hline $11 / 24 / 25$ rule & R or K at positions 11, 24, or 25 is related to X4-tropic makeup & - & - \\
\hline Net charge & K+R - (D+E) $\geq 5$ is associated with an X4-tropic makeup & Low & High \\
\hline Wetcat & $\begin{array}{l}\text { HIV tropism predictions measure inferred from genotypic/ } \\
\text { makeup paired dataset using applied statistical ways. }\end{array}$ & $22 \%$ \\
\hline Geno2pheno & $\begin{array}{l}\text { These algorithms for HIV tropism interpretation square } \\
\text { measure freely obtainable on websites. }\end{array}$ & $50 \%$ & $90 \%$ \\
\hline WebPSSM & \multicolumn{1}{|c}{-} & $84 \%$ & $96 \%$ \\
\hline
\end{tabular}

\section{CLINICAL EFFICIENCY OF CCR5 INHIBITOTRS}

\section{Clinical efficiency of Maraviroc}

As Maraviroc is only active against R-5 tropic virus and not against CXCR4 or dual-tropic virus. The maraviroc potency of the HIV-1 virus was studied during the 10day phase I trial of monotherapy in 63 patients which were previously reported with R-5 tropism. Randomized allocation of patients to treatment with maraviroc $25 \mathrm{mg}$, $100 \mathrm{mg}, 300 \mathrm{mg}$ once daily (QD) or $50 \mathrm{mg}, 100 \mathrm{mg}$, $150 \mathrm{mg}$ twice daily(bid) or placebo for ten days was done. On day 11, mean decrease of viral copies were found to be more in patients treated with maraviroc in comparison to placebo. No difference was reported in the reduction of viral copies in patients who were fasted vs fed individuals ${ }^{22}$. In phase II maraviroc efficacy was also determined in patients pretreated with mixed CXCR4 and R5 tropic virus. In maraviroc treated patients the CD4 cell count was shown to be increased, with a change in CD4 cells $/ \mathrm{mm}^{3}+36,+62$, and +60 in placebo group, 150mg (bid) and 150mg (QD) maraviroc respectively ${ }^{11}$. Further maraviroc is studied for phaseIII trials, in exclusively pretreated HIV-1 patients. In 2007, 
maraviroc was being evaluated in phase III studies MOTIVATE-1 (the USA and Canada) and MOTIVATE-2 (Europe, Australia, and theUSA) in previously treated and ART-naïve subjects in the study of Pfizer. Maraviroc approved by USFDA in 2007 for pretreated patients ${ }^{23}$.

Table 3: Efficacy of maraviroc in trials ${ }^{22}$

\begin{tabular}{|l|l|}
\hline Doses of the Drug & $\begin{array}{l}\text { Mean changes in viral load } \log _{10} \\
\text { copies/ ml ranges at day 11 }\end{array}$ \\
\hline $25 \mathrm{mg}$ QD & -0.03 \\
\hline $100 \mathrm{mg}$ QD & -1.43 \\
\hline $300 \mathrm{mg}$ QD & -1.35 \\
\hline $50 \mathrm{mg}$ bid & -0.66 \\
\hline $100 \mathrm{mg}$ bid & -1.42 \\
\hline $150 \mathrm{mg}$ bid(fed) & -1.34 \\
\hline
\end{tabular}

\section{Clinical efficiency of Vicriviroc}

A 14 days phase Imonotherapy study in 48 HIV-naïve patients were studied. The patients were treated with $10 \mathrm{mg}, 25 \mathrm{mg}$, and $50 \mathrm{mg}$ bid for 14 days in a randomized design. Decrease in viral copies weredose-related and the mean $\log _{10} \mathrm{c} / \mathrm{ml}$ drop of $-1.62(50 \mathrm{mg}$ bid), $1.56\left(25 \mathrm{mg}\right.$ bid) and $-1.08(10 \mathrm{mg} \text { bid })^{24,25}$. In phase II study is also performed in 92 treatment naïve patients, but the study was terminated due to early virologic breakthrough $^{26}$. The patients are divided into randomized groups to receive vicriviroc with doses of $25 \mathrm{mg}, 50 \mathrm{mg}$, $75 \mathrm{mg}$ once daily and placebo (efavirenz) for 14 days against the AZT/3TCbackground. After two weeks the treatment provides promising results. Duration of this study was 48 weeks, but at 32 weeks this study was terminated due to early viral breakthrough.

A double-blind, randomized trial was studied for phase II in 118 patients who experienced the viral breakthrough. In this study, patients received $5 \mathrm{mg}$, $10 \mathrm{mg}$, and $15 \mathrm{mg}$ vicriviroc as an add-on to the failing ritonavir containing HAART. Background treatment was optimized after 14 days of treatment. Study with $5 \mathrm{mg}$ vicriviroc dose was discontinued due to high virologic failure ${ }^{27,28,29}$. An extended follow-up study for phase II for higher doses gives promising results. In $70 \%$ patients the mean viral load declines with $<50$ copies $/ \mathrm{ml}$ at $24^{\text {th }}$ week and continued to have $<50$ copies $/ \mathrm{ml}$ at week $48^{30}$. Vicriviroc was halted in phase III clinical trials because of increased liver malignancies ${ }^{31}$.

Table 4: Efficacy of vicriviroc in trials ${ }^{24}$

\begin{tabular}{|l|l|}
\hline Dose(QD) & $\begin{array}{l}\text { Mean changes in viral load } \log _{10} \\
\text { copies/ } \mathrm{ml} \text { ranges at day } 15\end{array}$ \\
\hline $10 \mathrm{mg}$ & -1.08 \\
\hline $25 \mathrm{mg}$ & -1.56 \\
\hline $50 \mathrm{mg}$ & -1.62 \\
\hline
\end{tabular}

\section{Clinical efficiency of Aplaviroc}

Aplaviroc also a CCR5 inhibitor and promising results are shown in phaseI and IIa study. A decrease was observed in viral load in $0 \%$ of the placebo group when compared with $17 \%$ of patients receiving $200 \mathrm{mg}$ aplaviroc QD, $200 \mathrm{mg}$ aplaviroc bid received by $75 \%$ of patients, $63 \%$ of those treated with $400 \mathrm{mg}$ aplaviroc QD and $100 \%$ of the patients who were receiving 600 $\mathrm{mg}$ aplaviroc bid after 10 days of treatment ${ }^{32}$. However, phaseIIb and III trials were discontinued because of hepatotoxicity ${ }^{33}$.

Table 5: Efficacy of aplaviroc in trials ${ }^{32}$

\begin{tabular}{|l|l|}
\hline Doses & $\begin{array}{l}\text { Mean changes in viral load } \log _{10} \\
\text { copies/ ml ranges at day 11 }\end{array}$ \\
\hline $200 \mathrm{mg}$ QD & -0.46 \\
\hline $200 \mathrm{mg}$ bid & -1.23 \\
\hline $400 \mathrm{mg}$ QD & -1.03 \\
\hline $600 \mathrm{mg}$ bid & -1.66 \\
\hline
\end{tabular}

\section{TOXICITY AND ADVERSE EVENTS}

In healthy volunteers,oral doses of maraviroc to $900 \mathrm{mg}$ was found to be well tolerated ${ }^{34}$. The common adverse effect reported with maraviroc includes nausea, dizziness, headache, gingivitis, and asthenia ${ }^{11,22}$. But at a $600 \mathrm{mg}$ dose or above, orthostatic hypotension occurred more frequently ${ }^{35}$. The safety profile of placebo and maraviroc treatment groups has no difference in a trial with nausea, headache, fatigue, and diarrhoea being most frequent in all groups. A slightly higher chance of drowsiness and respiratory infections was accounted in the maraviroc treated groups ${ }^{36,37}$.

The 48 weeks phase II trial of vicriviroc showed overall good tolerability. No significant differences in adverse effects were seen between the different treatments of vicriviroc $(5 \mathrm{mg}, 10 \mathrm{mg}$, and $15 \mathrm{mg}$ ) with placebo. No prolongation of QT interval was reported. ${ }^{38}$

\section{MALIGNANCIES}

In 2006, the ACTG 5211 trial amongst antiretroviraltherapy-treated adults with the R5 tropic virus who received $10-15 \mathrm{mg}$ QD ritonavir-boosted vicriviroc was unblended because of the unexpected production of malignant lymphomas ${ }^{39}$. In patients, randomized in a clinical trial of vicriviroc fatalities occurred in 6 patients with maraviroc and two patients with placebo, from which one had been exposed to vicriviroc treatment for three months. From 6 subjects of vicriviroc group, one was diagnosed with gastric adenoma and one with human papillomavirus-related cell carcinoma, two developed non-Hodgkin lymphoma, and two developed $\mathrm{m}$. Hodgkin (1 had a history of treated Hodgkin disease) ${ }^{28}$. The associations of occurrence of malignancies with vicriviroc treatment remain uncertain but appear to be not drug-related. The data that was available recently through ACTG study showed that there was no further development of malignancies. There is a need for further development to follow up this possible relation of vicriviroc use and malignancies. The data obtained from MOTIVATE 1 and 2 showed that there was no significant difference in the production of malignancies between maraviroc treated patients and placebo groups ${ }^{35}$. 


\section{PHARMACOKINETICS OF CCR5 INHIBITORS}

The pharmacokinetic study of HIV-1 patients revealed that maraviroc is absorbed rapidly with a $\mathrm{T}_{\max }$ (time to maximum concentration) between 1-4 hours postdose. The plasma half-life $\left(\mathrm{t}_{1 / 2}\right)$ is from $16-23$ hours and is dose dependent ${ }^{22,}{ }^{34}$. In the presence of food, vicriviroc is absorbed rapidly with $\mathrm{T}_{\max }$ of approximately 2-3 hours. The plasma $t_{1 / 2}$ of vicriviroc is $28-32$ hours; this data supports that the dose should be once daily ${ }^{25}$. 40 . A phase I trial in 24- patients with R5 tropic virus revealed that the steady-state concentration of maraviroc was achieved in 7 days and a fastedstate, the plasma concentration lowered up to $50 \%$. The antiviral effect of maraviroc with dosing of the $150 \mathrm{mg}$ bid was found to be independent of food intake and reduces the viral load $1.45 \log _{10}$ copies $/ \mathrm{ml}$ and $1.34 \log _{10}$ copies $/ \mathrm{ml}$ for fasted and fed condition respectively. The study showed thatthere was no significant effect of food on vicriviroc pharmacokinetic profile. The vicriviroc can be administered with or without food ${ }^{41}$.

\section{DRUG INTERACTION}

The vicriviroc and maraviroc both are primarily metabolized by CYP3A4, an enzyme that is a member of cytochrome $\mathrm{P} 450$ system. When vicriviroc and maraviroc are co-administered with potent CYP3A4 inducer, the drug levels may decrease, and the drug levels may increase when these are co administered with potent CYP3A4 inhibitor. Therefore the drug-drug interactions can be possible especially with a protease inhibitor. Dose of maraviroc reduces up to $50 \%$ in presence of protease inhibitor. Consequently, there is a recommendation for potent CYP3A4 inhibitor. An exceptionis with tipranavir which does not lead to any substantial changes, in maraviroc exposure in healthy participants ${ }^{42}$. When protease inhibitor is absent the maraviroc is given with rifampin, the dose of maraviroc has to be doubled ${ }^{43}$.Maraviroc and Vicriviroc shows no significant inhibitory effects on any CYP450 enzyme, by making it unlikely that they can alter the metabolism of those drugs which are metabolized by cytochrome $450^{43}$, 44. Pharmacokinetics studies on healthy volunteers showed that maraviroc does not affect the pK of NRTIs Zidovudine(AZT), Lamivudine (3TC) and Tenofovir(TDF). Metabolism characteristics of the vicriviroc are same to maraviroc.There are no clinically relevant effects on plasma exposure of vicriviroc, AZT, 3TC, and TDF when co-administered to healthy subjects ${ }^{45,46}$. When vicriviroc $10 \mathrm{mg}$ QD co-administered with $600 \mathrm{mg}$ efavirenzQD resulted in $81 \%$ decrease in AUC of vicriviroc ${ }^{47}$. When vicriviroc is co-administered with LPV, the AUC increased by 4.2 fold. The currently reported dose of $100 \mathrm{mg}$ ritonavir bid $+15 \mathrm{mg}$ vicriviroc leads to comparable vicriviroc levels as when $15 \mathrm{mg}$ is added to ritonavir-boosted PI. Therefore, in future vicriviroc will be added to the ritonavir-boosted Protease Inhibitor (PI) regimen without any dose adaptation $^{48}$.

Table 6: Summary of drug interactions

\begin{tabular}{|l|l|l|}
\hline Drug Name & Effect on Maraviroc Exposure Levels & Effect on Dose of Maraviroc \\
\hline Atazanavir & $\uparrow$ (5 fold) & $\downarrow$ (by $50 \%)$ \\
\hline Darunavir & $\uparrow$ (4 fold) & $\downarrow$ (by $50 \%)$ \\
\hline Efavirenz & $\downarrow$ (by half) & $\begin{array}{l}\text { Double (in the absence of PIs), } \\
\text { (in the presence of a boosting dose of ritonavir) }\end{array}$ \\
\hline Ketoconazole & $\uparrow$ (5 fold) & $\downarrow$ (by $50 \%)$ \\
\hline Rifampin & $\downarrow$ (by one third) & Double (in the absence of PIs) \\
\hline Lopinavir & $\uparrow$ (4 fold) & $\downarrow$ (by $50 \%)$ \\
\hline Tipranavir & No change & No dose modification \\
\hline Ritonavir & $\uparrow$ (by 2.6 fold) & $\downarrow$ (by $50 \%)$ \\
\hline
\end{tabular}

\section{CHALLENGES WITH MARAVIROC TREATMENT}

There are approximately not more than $50 \%$ pretreated patients, infected with the R5 tropic virus and are possible subjects to maraviroc treatment and the remaining almost of $50 \%$ of patients with virologic failure owing to HAART resistance are not expected to benefit from maraviroctreatment. Before initiation of the therapy, it is essential to differentiate between R5 or R4 tropic virus. The first requirement of this assay is highintensity viral load $>500$ copies per $\mathrm{ml}$, and the major problem with this assay is the cost, i.e. $\$ 1500-2000$ per single test and the blood samples are shipped to the US for this assay ${ }^{49}$.

\section{CONCLUSION}

Inside the mild of growing viral resistance in opposition to current antiretroviral drugs, the current improvement of this new class of ARV-therapy with a totally novel mechanism of action is beneficial. The CCR5antagonists maraviroc and vicriviroc are energetic against current 3 drug-class-resistant R5-tropic HIV-1. The two substances have indicated powerful antiretroviral action in pre-treated individuals with extreme HIV-disease. The trial results of maraviroc are promising. Vicriviroc was defied with more limitations on its way of clinical assessment. Nevertheless, after preliminary concerns associated with virologic breakthrough in low-dose treatment, sustained antiviral action of vicriviroc can also be suggested as long because it was boosted with ritonavir. Problems 
concerning the presence of malignancies in patients treated with vicriviroc could not be affirmed in to boot follow-up assessment of this drug. The CCR5 antagonists are mostly metabolized by the manner of CYP3A4 framework. They don't repress or induce CYP450 at normal concentrations; however the coadministration of CYP3A4-inducers or -inhibitors may have influence on pharmacokinetics of vicriviroc and maraviroc. Consequently, when CCR5 antagonists are combined with different (ARV) drugs dose adjustments can be essential. Herewith two effective new antiretroviral devices are introduced in HIV work on, opening new treatment open doors for patients with multi-resistant strains of HIV. After the maraviroc approvel, the first CCR5 inhibitor in the treatment of HIV-1 infection, trofile testing is required for clinical use. The European concord group on clinical management of trofile testing gives a summary of obtainable published work, evidence-based proposals for the clinical utilization of trofile testing, and directions on uncertain components and improvements. Current information lend support to each the utilization of population genotyping and also the commercially out there increased sensitivity assay for establishing coreceptor response.

\section{ACKNOWLEDGEMENT}

We are highly thankful to Department of Pharmaceutical Sciences, Kumaun University Campus Bhimtal to provide support and help to this study. We are also thankful to Jyotsna Dwivedi and Mohammed Adil for help.

\section{REFERENCES}

1. World Health Organization, the Public Health Response to Pretreatment HIV Drug Resistance, WHO Guidel. (2017).

2. Carpenter C, Fischl MA, Hammer SM, Hirsch MS, Jacobsen DM, Katzenstein DA, et al. Antiretroviral Therapy for HIV Infection in1998. American Medical Association. 1998; 280(1):78.

3. Nichols WG, Steel HM, Adkison K, Curtis L, Millard J, Kabeya $\mathrm{K}$, et al. Hepatotoxicity observed in clinical trials of aplaviroc. Antimicrobial agents and chemotherapy. 2008; 52(3):858-865

4. Cocchi F, DeVico AL, Garzino-Demo A, Arya SK, Gallo RC, Lusso P. Identification of RANTES, MIP-1 alpha, and MIP-1 beta as the major HIV-suppressive factors produced by CD8+ T cells. Science 1995; 270:1811-5.

5. Cohen C, DeJesus E, Mills A, et al. Potent antiretroviral activity of the once-daily CCR5 antagonist INCB009471 over 14 days of monotherapy [Abstract TUAB106]. In: 4th IAS Conference on HIV Pathogenesis, Treatment and Prevention 2007, Sydney, Australia.

6. Shin N, Solomon K, Wang KH, et al. INCB9471 is a noncompetitive small molecule antagonist of CCR5 [Abstract H1032]. Presented at: 47th Interscience Conference on Antimicrobial Agents and Chemotherapy; 2007; Chicago, IL.

7. Solomon K, Baribaud F, Shin N, et al. INCB9471 is a potent inhibitor of R5HIV-1 infection in vitro [Abstract H-1033]. Presented at: 47th Interscience Conference on Antimicrobial Agents and Chemotherapy; 2007; Chicago, IL.

8. Jaysuriya H, Herath KB, Ondekya JG, Polishook JD, Gerald $\mathrm{F}$, Drombrowski $\mathrm{AW}$, et al. Isolation and structure of antagonists of chemokine receptor (CCR5). Journal of Natural Products 2004; 67:1036-1038.

9. Baba M, Takashima K, Miyake H, et al. TAK-652 inhibits CCR5-mediated human immunodeficiency virus type 1 infection in vitro and has favorable pharmacokinetics in humans. Antimicrobial Agents and Chemotherapy. 2005; 49(11):4584-4591.

10. Samson M, Libert F, Doranz BJ, et al. Resistance to HIV-1 infection in caucasian individuals bearing mutant alleles of the CCR-5 chemokine receptor gene. Nature 1996; 382(6593):722-5

11. Mayer H, van der Ryst E, Saag M, et al. Safety and efficacy of maraviroc, a novel CCR5 antagonist, when used in combination with optimized background therapy for the treatment of antiretroviral-experienced subjects infected with dual/mixed-tropic HIV-1: 24-week results of a phase $2 b$ exploratory trial [abstract ThLB0215]. Presented at: XVI International AIDS Conference (IAC); 2006; Toronto [accessed 12june2018]https://quod.lib.umich.edu/c/cohenaids/5571095. $0191.008 / 2$ ?view $=$ image $\&$ size $=400$

12. VandekerckhoveLPR, WensingAMJ, Kaiser R, Brun-Vézinet F, Clotet B, Luca AD, Dressler S, et al. European guidelines

on the clinical management of HIV-1 tropism testing; Lancet Infect Dis 2011; 11:394-407

13. Tremblay C, Hardy I, Lalonde R, et al. HIV-1 tropism testingand clinical management of CCR5 antagonists: Quebec reviewand recommendations. Can J Infect Dis Med Microbiol 2013' 24(4):202-208

14. Hamy F, Vidal V, Hubert S, Klimkait T. Hybridization-based assay andreplicative phenotyping as diagnostic platform for determination of coreceptortropism [Abstract 60]. Presented at: 5th European HIV Drug Resistance Workshop; 2007; Monte Carlo.

15. Van Baelen K, Vandenbrouke I, Rondelez E, Van Eygen V, Vermeiren H,Stuyver L. HIV-1 coreceptor usage determination in clinical isolates usingclonal and populationbased genotypic and phenotypic assays. J Virol Methods. 2007; 146:61-73

16. Isaka Y, Sato A, Miki S, et al. Small amino acid changes in the V3 loop Of HIV type 2 determines the coreceptor usage for CXCR4 and CCR5.Virology. 1999' 264:237-43.

17. Seclen E, Poveda E, Garrido C, et al. High sensitivity to detect $\mathrm{X} 4$ variantsusing specific genotypic tools in antiretroviral-experienced HIV patients suitable to CCR5 antagonists therapy. J AntimicrobChemother.2010; 65:148692

18. Briggs D, Tuttle D, Sleasman J, et al. Envelope V3 amino acid sequencepredicts HIV-1 phenotype (co-receptor usage and tropism for macrophages).AIDS. 2000; 14:2937-9

19. Delobel P, Nugeyre M, Cazabat M, et al. Population-based sequencingof the V3 region of env for predicting the coreceptor usage of HIV type1 quasispecies. J Clin Microbiol. 2007, 45:1572-80

20. Hoffman N, Seillier-Moiseiwitsch F, Anh J, et al. Variability in the HIV type1 gp120 Env protein linked to phenotypeassociated changes in the V3loop. J Virol. 2002; 76:3852-64

21. Sierra S, Kaiser R, Thielen A, et al. Genotypic coreceptor analysis. Eur J Med Res. 2007; 12:453-62

22. Fatkenheuer G, Pozniak AL, Johnson MA, et al. Efficacy of short-term monotherapy with maraviroc, a new CCR5 antagonist, in patients infected with HIV-1. Nat Med 2005; 11(11):1170-2

23. Profit L.Maraviroc: the evidence for its potential in the management of HIV. Core Evidence 2007; 2(1):1-14

24. Schürmann D, Rouzier R, Nourgarede R. SCH D: Antiviral activity of a CCR5 receptor antagonist [Abstract 140LB]. Presented at: 11th CROI; 2004; San Francisco.

25. Schurmann D, Pechardscheck C, Rouzier R, et al. SCH 417690: antiviral activity of a potent new CCR5 receptor antagonist[Abstract TuOa0205]. Presented at: 3rd IAS Conference on HIV Pathogenesis and Treatment; 2005 July 24-27; Rio de Janeiro, Brazil.

26. Greaves W, Landovitz R, Fatkenheuer G et al. Late virologic breakthrough in treatment-naïve patients on a regimen of 
combivir plus vicriviroc [Abstract 161LB]. Presented at: XIII CROI; 2006; Denver.

27. Gulick R, Su Z, Flexner C, et al. ACTG 5211: phase 2 study of the safety and efficacy of vicriviroc in HIV-infected treatment-experienced subjects [Abstract ThLB0217].Presented at: XVI IAC; 2006; Toronto.

28. Gulick R, Su Z, Flexner C et al. Phase 2 Study of the Safety and Efficacy of Vicriviroc, a CCR5 Inhibitor, in HIV-1Infected, Treatment-Experienced Patients: AIDS Clinical Trials Group 5211. J Infect Dis 2007; 196(2):304-12

29. Tremblay CL, Giguel F, Kollmann C, et al. Anti-human immunodeficiency virus interactions of $\mathrm{SCH}-\mathrm{C}(\mathrm{SCH}$ 351125), a CCR5 antagonist, with other antiretroviral agents in vitro. Antimicrob Agents Chemother 2002; 46:1336-9.

30. Gulick R, Su Z, Flexner C et al. ACTG 5211: phase II study of the safety and efficacy of vicriviroc (VCV) in HIVinfected treatment-experienced subjects: 48 week results [Abstract TUAB102]. Presented at: 4th IAS Conference; 2007.

31. Shah HR., Savjani JK.Recent updates for designing CCR5 antagonists as anti-retroviral agents. European Journal of Medicinal Chemistry2018, 147:115-129.

32. Lalezari J, Thompson M, Kumar P, et al. Antiviral activity and safety of 873140, a novel CCR5 antagonist, during shortterm monotherapy in HIV-infected adults. AIDS 2005, 19(14): 1443-48

33. Crabb C. GlaxoSmithKline ends aplaviroc trials. AIDS 2006, 20: 641

34. Abel SE, VanderRyst GJ, Muirhead M, Rosario A, Edgington G, Weissgerber. Pharmacokinetics of Single and Multiple Oral Doses of UK-427,857-A Novel CCR5 Antagonist in Healthy Volunteers [Abstract 547]. Presented at: 10th CROI; February 2003; Boston, USA.

35. McHale M., et al. Overview of phase 1 and 2 a safety and efficacy data of maraviroc (UK-427,857) [Abstract TuOa0204]. Presented at: The 3rd IAS Conference on HIV Pathogenesis and Treatment; 2005.

36. Lalezari J, Goodrich J, DeJesus E et al. Efficacy and Safety of Maraviroc plus Optimized Background Therapy in Viremic ART-experienced Patients Infected with CCR5tropic HIV-1: 24-Week Results of a Phase 2b/3 Study in the US and Canada[Abstract 104bLB]. Presented at: 14th CROI; 2007; Los Angeles.

37. Nelson M, Fatkenheuer G, Kounourina I et al. Efficacy and Safety of Maraviroc plus Optimized Background Therapy in Viremic, ART-experienced Patients Infected with CCR5tropic HIV-1 in Europe, Australia, and North America: 24Week Results[Abstract 104aLB]. Presented at: 14th CROI; 2007; Los Angeles.

38. Carl J, Lenz C, Rgen J, Rockstroh K. Vicriviroc, a new CCchemokine receptor 5 inhibitor for treatment of HIV: properties, promises and challenges. Expert Opin. Drug Metab. Toxicol. 2010; 6(9):1139-1150

39. Schering-Plough provides update on phase II study of vicriviroc: study continues in HIV treatment experienced patients (press release). Schering-Plough Corp, March 3, 2006

40. Strizki JM, Tremblay C, Xu S, et al. Discovery and characterization of vicriviroc ( $\mathrm{SCH} 417690)$, a R5 antagonist with potent activity against human immunodeficiency virus type 1. Antimicrob Agents Chemother 2005; 49:4911-9

41. Keung A, Sansone A, Caceres M, Kraan M, Gaillac B. Effect of Food on Bioavailability of $\mathrm{SCH} 417690$ in Healthy Volunteers [abstract A-1200]. Presented at: 45th Interscience Conference on Antimicrobial Agents and Chemotherapy; December 16-19, 2005; Washington.

42. Abel S, et al. Effect of boosted tipranavir on the pharmacokinetics of maraviroc (UK 427,857) in healthy volunteers [abstract LBPE4.3/15]. Presented at: 10th European AIDS Conference; November 17-20, 2005; Dublin.

43. Abel S, Russell D, Ridgway C, Muirhead G. Overview of the drug-drug interaction data for maraviroc (UK427,857). Presented at: 6th International Workshop on Clinical Pharmacology of HIV Therapy [Abstract 76]. April 28-30, 2005; Quebec City, Canada.

44. Muirhead G, Pozniak A, Gazzard B, Nelson M, Moyle G, Ridgway C, Taylor-Worth R, Russell D. A Novel Probe Drug Interaction Study to Investigate the Effect of Selected ARV Combinations on the Pharmacokinetics of a Single Oral Dose of UK-427,857 in $\mathrm{HIV}^{+}$ve Subjects[Abstract 663]. Presented at: 12th Retroconference on Retroviruses and Opportunistic Infections; February 22-25, 2005; Boston, USA.

45. Sansone A, Guillaume M, Kraan M, Keung A, Caceres M, Boutros T. The pharmacokinetics of SCH 417690 when administered alone and in combination with lamivudine/ zidovudine[Abstract 84]. Presented at: 6th International Workshop on Clinical Pharmacology of HIV Therapy; April 28-30, 2005; Quebec City, Canada.

46. Sansone A, Guillaume M, Kraan M, Soni P, Keung A, Boutros T. Pharmacokinetics of SCH 417690 administered alone and in combination with tenofovir [Abstract 85]. Presented at: 6th International Workshop on Clinical Pharmacology of HIV Therapy; April 28-30, 2005; Quebec City, Canada.

47. Saltzman M, Rosenberg M, Kraan M, Keung A, Boutros T, Soni P, Sansone A. Pharmacokinetics of SCH417690 administered alone or in combination with ritonavir and efavirenz in healthy volunteers [Abstract TuPe3.1.B08]. Presented at: 3rd IAS Conference on HIV Pathogenesis and Treatment; July 24-27, 2005; Rio de Janeiro, Brazil.

48. Sansone A, Keung A, Tetteh E, Weisbrot H, Martinho M, Lang S, et al.Pharmacokinetics of vicriviroc are not affected in combination with five different protease inhibitors boosted by ritonavir [Abstract 582]. Presented at: 13th Conference on Retroviruses and Opportunistic Infections; February 5-8, 2006; Denver.

49. Emmelkamp JM, Rockstroh JK. Maraviroc, risks and benefits: a review of the clinical literature. Expert Opin. Drug Saf. 2008; 7(5):559-569 